\title{
The Influence of Consumer Affinity on Revisit Intention over time_-A Case Study Chinese Tourists' Perception of Thailand
}

\author{
Yan-ping $\mathrm{SHI}^{1 *}$ \\ ${ }^{1}$ Guizhou University of Commerce, Management School, Guiyang, Guizhou, China
}

\begin{abstract}
Revisiting tourists can bring great benefits to the tourism industry, which has attracted the attention of scholars, but few scholars have studied the consumer affinity as the influence factor of the revisit intention. This study constructs the relationship model between consumer affinity and revisit intention, and uses questionnaire method to collect data and apply multi-layer regression analysis to process data. The study found that cultural affinity and people affinity have a significant positive impact on short-term revisit intention, cultural affinity has a significant positive impact on mid-term revisit intention, landscape affinity and people affinity have a significant positive impact on long-term re-visiting intentions. The conclusion of this paper has some practical guiding significance for outbound tourism propaganda, and some practical guiding significance for Thailand, to improve the trip of Chinese tourists.
\end{abstract}

\section{Introduction}

In recent years, the number of outbound tourists in China has increased rapidly, and China has become the largest source of outbound tourists in the world. It is pointed out that the rate of revisit to the destination of outbound tourism in China has increased.The revisit rate of tourist destination is an important index to measure the satisfaction and recognition of tourists to the destination. When the conditions are ripe, the revisit intention is likely to be transformed into revisit behavior. Few scholars pay attention to the behavior of revisiting across borders. Consumer affinity is the affection and attachment of consumers to a particular country. The idea of consumer affinity comes from 2008. The research on the influence of consumer affinity is mainly on consumers' willingness to buy and pay. A few scholars have discussed the influence of consumer affinity on tourism willingness. However, there are no scholars to explore the impact of consumer affinity on the revisit intention. And the willingness to revisit will change over time. When consumers have good intentions towards a particular country, will the revisit intention change with time? And according to the attachment theory, when consumers show affinity to a country, consumers will choose to revisit the country to express their love and attachment to the country. These are all issues that need to be further explored.

Thailand is loved by the Chinese people because of its proximity to China and its unique culture. According to the Thai Tourism Administration, 10.98 million Chinese tourists visited Thailand in 2019. In summary, this paper divides the willingness to revisit into short-term revisit intention, mid-term revisit intention and long-term revisit intention according to the time. Taking Thailand as the target country and Chinese citizens who have experienced
Thai tourism as the research object, this paper discusses the influence of consumer affinity on short-term revisit intention, mid-term revisit intention and long-term revisit intention. The research of this paper has certain reference significance for the management of the target good intention country, the marketing strategy and the formulation of the marketing strategy of the international tourism company of our country.

\section{Literature Review and Research hypothesis}

\subsection{Consumer affinity}

Consumer affinity refers to the love, resonance and even attachment of consumers to a particular country because of their own experience or subjective cognition (Oberecker \& Diamantopoulos, 2008). Consumer affinity is a positive positive emotion relative to consumer hostility (Wongtada et al.,2012). Personal experience is an important factor causing consumer affinity, but it is by no means the decisive factor of consumer affinity. Today, with rich information, consumers can recognize a particular country through a variety of information, thus generating affinty to that country. Nes et al.(2014) have made a more comprehensive classification of the factors leading to consumer affinity, including culture/landscape affinity, music/entertainment affinity, people affinity, political affinity and general affinity. Chinese scholars take Chinese consumers as the research object, and define the factors leading to consumer affinity as cultural affinity, landscape affinity and people affinity (Yang et al.,2018). 


\subsection{Revisit intention}

Revisit intention in this study refers to the revisit to a country. According to previous studies, it is defined as the possibility of tourists returning to the destination country and carrying out tourism activities on the original scenic spots or scenic spots that have not been visited(Baker \& Crompton,2000; Kozak,2001). When tourists return to the destination country for revisit is a question worth discussing. Some scholars have found that their willingness to revisit will change with time(Baloglue \& Erickson,1998). According to the above research, this paper divides the willingness to revisit into short-term revisit intention, mid-term revisit intention and long-term revisit intention. The willingness to revisit within one year is defined as short-term revisit intention, the revisit willingness within one to three years is defined as midterm revisit intention, and the revisit willingness after three years is defined as long-term revisit intention (Oppermann ,1998;Jang \& Feng,2007).

\subsection{Impact of consumer affinity on revisit intention}

Most scholars have carried out the influence of consumer affinity on purchase intention, and found that consumer affinity has a significant positive impact on purchase willingness (Oberecker \& Diamantopoulos, 2008; Wongtada et al.,2012; Nes et al.,2014). Tourism is a special and important product form(Gou \& Zhou,2016). Consumer affinity has a positive effect on the intention to travel abroad, and its positive effect is much greater than the negative effect of consumer hostility on the intention to travel abroad(Yang et al.,2018).

When Chinese citizens have affinity towards Thailand and express positive feelings, according to the theory of Social Identity, Chinese citizens will regard Thailand as an inner group. Consumer affinity makes consumers attached to a particular country. If consumers become attached to a place, they will want to keep in touch with that place to maintain their attachment to that place according to attachment theory. It has been found that local attachment has a positive impact on revisiting (Prayag \& Ryan,2011).

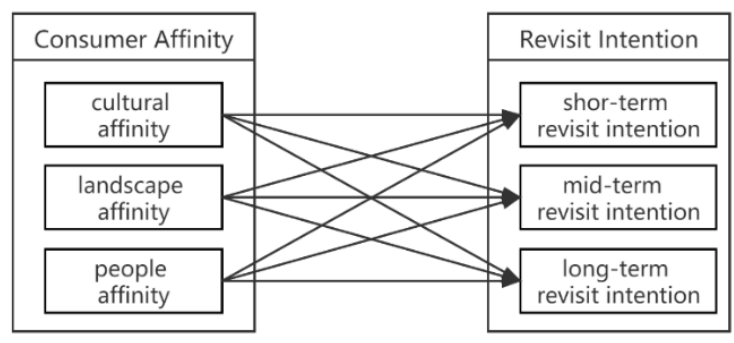

Fig. 1. A conceptual model

Consumer affinity is divided into three dimensions: cultural affinity, landscape affinity and people affinity, and the revisit intention is divided into short-term, mid-term and long-term revisit intention. Hence, the following hypothesis is proposed:

Hl. Consumer affinity has a significant positive impact on the revisit intention in the short term, Consumer affinity includs cultural affinity, landscape affinity and people affinity, then hypothesis is proposed as $\mathrm{H} 1 \mathrm{a}, \mathrm{H} 1 \mathrm{~b}$ and $\mathrm{H} 1 \mathrm{c}$.

$\mathrm{H} 2$. Consumer affinity has a significant positive impact on the revisit intention in the mid term, Consumer affinity includs cultural affinity, landscape affinity and people affinity, then hypothesis is proposed as $\mathrm{H} 2 \mathrm{a}, \mathrm{H} 2 \mathrm{~b}$ and $\mathrm{H} 2 \mathrm{c}$.

H3. Consumer affinity has a significant positive impact on the revisit intention in the long term, Consumer affinity includs cultural affinity, landscape affinity and people affinity, then hypothesis is proposed as $\mathrm{H} 3 \mathrm{a}, \mathrm{H} 3 \mathrm{~b}$ and $\mathrm{H} 3 \mathrm{c}$.

\section{Method}

\subsection{Measures}

There are three parts: consumer affinity, revisit intention, and personal information.

\subsubsection{Consumer affinity}

A fourteen-item scale developed by Yang et al. (2018) was used to measure consumer affinity. Respondents fill out questionnaires on a five-point Likert-type scale ranging from strongly disagree (1) to strongly agree (5).Cultural affinity includes five items, such as "I like Thai culture" and "I like Thai art". Landscape affinity includes "I like the natural scenery of Thailand", "Thailand has a lot of magnificent scenery, I like it very much" and so on. People affinity includes "I think the Thai people are open and friendly to foreigners", "Thai people are simple and kind, I like it very much", and so on. The item, in which "I don't like Thais" is a discriminant reverse question.

\subsubsection{Revisit intention}

The scale of revisit intention comes from Jang and Feng(2007). It was divided into short-term revisit intention (within one year), mid-term revisit intention (within one to three years) and long-term revisit intention (three years later). The behavioral willingness was measured by "revisit interest", such as "I am interested in traveling to Thailand again in the next year", and expectations were measured by "possibility". For example, "I am very likely to travel to Thailand again in the next year", with a total of six topics.

\subsection{Data collection and sample}

In this study, convenient sampling and snowball sampling were combined to collect questionnaires through two ways, and targeted questionnaires were sent out. The first way, investigators sent out paper questionnaires to the relatives and friends who have experienced traveling in Thailand, asking them to help fill out the questionnaires. Investigators also invited friends to join the questionnaire, asking friends to send the questionnaire to other friends who have had Thai travel experience. The second way, investigators invited Chinese tourists who have just 
finished their trip to fill out the questionnaire at Suvarnabhumi Airport in Bangkok. In order to increase the filling quality of the sample, it was avoided that all the members of the same family fill out the questionnaire and the person under investigation must be over 15 years of age(Kozak \& Rimmington,2000). The sample subjects involved 22 provinces, such as Jiangsu, Shanxi, Sichuan, Guangdong, Shanghai and Beijing et al. The analysis of personal basic information was as follows: the proportion of women was higher than that of men, accounting for $66.3 \%$ and $31.7 \%$, and accounting for $65 \%$ of the respondents aged 25-44. Married person accounted for $70 \%$ of the sample, $57 \%$ of the total number of people with a college degree, $40 \%$ of graduate students or above; in occupation, the number of teachers / researchers is the largest, up to $37.4 \%$, followed by $20 \%$ of company employees; in personal monthly income, the proportion of people earning $5000-10000 \mathrm{RMB}$ is $48 \%$, and the number of people earning $10000-20000 \mathrm{RMB}$ is $20 \%$. The analysis of tourism characteristics was as follows: $59 \%$ of the people had been to Thailand once and $27 \%$ of them had been to Thailand three or more times; nearly $50 \%$ of them were self-help tours and 33\% choosed to report for tour groups. $52 \%$ of the respondents stayed in Thailand for less than seven days , and $25 \%$ of them stayed in Thailand within 15 days, and $18 \%$ of them stayed in Thailand for more than a month.

\section{RESULTS}

\subsection{Measurement model}

The construction validity test of the scale is mainly through the test of the construction validity of the scale. The verification factor analysis was carried out by software, and the data was calculated, $\mathrm{X}^{2}=372.299$,

$\mathrm{Df}=137, \quad \mathrm{X}^{2} / \mathrm{df}=2.753(<3), \quad \mathrm{RMSEA}=0.073(<0.08)$, $\mathrm{NFI}=0.934(>0.9), \quad \mathrm{RFI}=0.917(>0.9), \quad \mathrm{IFI}=0.957(>0.9)$, $\mathrm{TLI}=0.946(>0.9), \quad \mathrm{CFI}=0.957(>0.9)$.

The Cronbach's $\alpha$ of all variables was between 0.860 0.924 , and the CR of all variables was between 0.864 0.925 , and the AVE of all variables was between 0.6800.854 . The results showed that the measurement model fitted well.

\subsection{Hypothesis testing}

The results of hierarchical regression analysis are shown in the table. It showed that when short-term revisit intention was taken as dependent variable, cultural affinity had a positive influence on short-term revisit intention( $\beta$ $=0.173, \mathrm{P}<0.05), \mathrm{H} 1 \mathrm{a}$ is supported; and people affinity had a significant positive impact on the short-term revisit intention $(\beta=0.176, \mathrm{P}<0.01)$, H1c is supported. When the mid-term revisit intention was taken as the dependent variable, cultural affinigy had a significant positive influence $(\beta=0.232, \mathrm{P}<0.001), \mathrm{H} 2 \mathrm{a}$ is supported. When the long-term revisit intention was taken as the dependent variable, landscape affinity had a positive effect on the long-term revisit intention $(\beta=0.157, \mathrm{P}<0.05), \mathrm{H} 3 \mathrm{~b}$ is supported; people affinity had a significant positive impact on long-term revisit intention $(\beta=0.274, \mathrm{P}<0.001)$, $\mathrm{H} 3 \mathrm{c}$ is supported.

Table 1. Regression analysis results.

\begin{tabular}{|c|c|c|c|c|c|c|c|}
\hline \multirow[t]{2}{*}{ Variables } & \multicolumn{2}{|c|}{$\begin{array}{l}\text { short-term revisit } \\
\text { intention }\end{array}$} & \multicolumn{2}{|c|}{$\begin{array}{l}\text { mid-term revisit } \\
\text { intention }\end{array}$} & \multicolumn{2}{|c|}{$\begin{array}{l}\text { long-term revisit } \\
\text { intention }\end{array}$} & \multirow[t]{2}{*}{ VIF } \\
\hline & M1 & M2 & M4 & M5 & M7 & M8 & \\
\hline gender & 0.017 & -0.007 & 0.051 & 0.033 & 0.047 & 0.017 & 1.128 \\
\hline age & -0.015 & -0.104 & -0.065 & $-0.148^{*}$ & -0.089 & $-0.178^{*}$ & 1.787 \\
\hline marital status & -0.075 & -0.041 & -0.015 & 0.025 & -0.085 & -0.050 & 1.722 \\
\hline education & 0.002 & 0.008 & -0.020 & 0.008 & -0.018 & 0.035 & 1.335 \\
\hline career & 0.014 & -0.049 & 0.030 & 0.000 & 0.054 & 0.042 & 1.299 \\
\hline income & $0.173^{*}$ & $0.123^{\circ}$ & $0.167^{*}$ & $0.154^{* \prime}$ & $0.181^{*}$ & $0.178^{*}$ & 1.513 \\
\hline type of travel & $-0.157^{* *}$ & -0.067 & $-0.129^{\circ}$ & -0.091 & -0.009 & 0.006 & 1.470 \\
\hline length of stay & $0.240^{\cdots}$ & 0.047 & $0.203^{*}$ & 0.040 & 0.107 & -0.061 & 1.631 \\
\hline cultural affinity & & $0.173^{\circ}$ & & $0.232^{\cdots}$ & & 0.131 & 2.724 \\
\hline landscape affinity & & 0.046 & & 0.142 & & $0.157^{*}$ & 2.484 \\
\hline people affinity & & $0.176^{\prime \prime}$ & & 0.110 & & $0.274^{\cdots}$ & 2.282 \\
\hline$\triangle \mathrm{F}$ & $6.424^{\cdots}$ & $21.839^{\cdots}$ & $4.285^{\cdots *}$ & $23.926^{* \cdots}$ & $1.961^{\circ}$ & $28.602^{\cdots}$ & \\
\hline $\mathrm{R}^{2}$ & $0.137^{\cdots \cdots}$ & $0.321^{\cdots}$ & $0.095^{\cdots}$ & $0.303^{\cdots}$ & $0.046^{\circ}$ & $0.297^{\cdots}$ & \\
\hline $\operatorname{adj} R^{2}$ & $0.115^{* *}$ & $0.296^{*}$ & $0.073^{\cdots}$ & $0.277^{\cdots}$ & $0.023^{\circ}$ & $0.270^{\cdots}$ & \\
\hline
\end{tabular}

\section{Discussion}

\subsection{Conclusions}

This study takes Thailand as the target affinity intention country, uses the questionnaire survey method to collect the data, uses the hierarchical regression analysis to process the data, and examines whether and how the three dimensions of consumer affinity have an impact on revisit intention over time. The following three conclusions have been drawn:

First, the short-term revisit intention is affected by cultural affinity and people affinity, and the influence of people affinity on the revisit intention is greater than that of cultural affinity. It shows that the driving force of Chinese citizens who have Thai tourism experience to revisit Thailand mainly comes from the recognition of people affinity and cultural affinity, but landscape affinity can not cause tourists to revisit in a short period of time.

Second, tourists' revisit intention in the mid-term is affected by cultural affinity, which shows that in the next one to three years, the driving force of revisiting to Thailand mainly comes from the recognition of Thai culture.

Landscape affinity and people affinity can not cause tourists to revisit in the mid term. This also shows that culture is formed by a country in the long process of historical development and is unique to a country. This is an important factor in attracting tourists from other countries to visit the country again.

Third, the long-term revisit intention is affected by landscape affinity and people affinity, and the impact of people affinity is greater than that of landscape affinity. The revisit intention for a long time mainly reflects the possibility of tourists traveling to Thailand after three years, which is different from the willingness to revisit in the short term and the mid term. Landscape affinity has a 
significant positive impact on the willingness to revisit for a long time. With the passage of time, the original familiar landscape has been gradually forgotten by tourists, refeeling the landscape of the target good country has become a driving force for tourists. Thailand is a smiling country, the Thai people are very kind, and the Thai people who feel kind again after three years are also the driving force of their willingness to revisit for a long time.

\subsection{Management implications}

The conclusions of this study reveal one of the reasons for the behavior of Chinese citizens to revisit abroad, provide a basis for improving the willingness of Chinese citizens to revisit abroad, and have enlightening significance for the propaganda practice of outbound tourism, which is reflected in the following aspects:

First, with the increasing attention to tourism in various countries, the global tourism industry is booming, and there are more and more homogeneous scenic spots. It is particularly important to understand the factors that consumers choose their destination when traveling abroad. This study shows that people affinity, cultural affinity and landscape affinity are very important when making revisit decisions in specific countries, which reminds Chinese tourists of their revisit behavior. Destination countries should constantly improve themselves to attract more tourists .

Second, attach importance to the creation of the overall image of the country. Thailand is known as "smiling country". Thailand has entered the top three most popular countries in the world for many years in a row. China should learn the strategy of building Thailand's overall national image, grasp the characteristics of our country, actively publicize abroad, enhance China's international tourism status, and then further enhance the soft power of our country.

\subsection{Limitations}

There are still some places worthy of discussion and improvement in many aspects of this study. There are some shortcomings to improve: first, this questionnaire survey mainly uses the method of convenient sampling, although the questionnaire is filled out from 22 provinces and municipalities directly under the Central Government, but $50 \%$ of the respondents come from the provinces in which the author is located, and the analysis results will inevitably be affected to a certain extent. Second, personal factors include age, gender, income, and so on. In the future study, we should further explore the role of other personal factors in regulating consumer affinity and revisit intention. Third, this study only uses the cross-section research data, and does not obtain the dynamic research data, which has a certain impact on the accurate verification and analysis of the causality between variables. In the future research, we should strengthen the long-term tracking of the subjects, the purpose is to draw a completely positive conclusion for the causality between the variables.

\section{References}

1. Oberecker, E. M., Diamantopoulos, R. A. (2008). The consumer affinity construct: conceptualization, qualitative investigation, and research agenda. J. Sci. Commun., 16(3), 23-56.

2. Wongtada, N., Rice,G., Bandyopadhyay, S. K. (2012). Developing and validating affinity: a new scale to measure consumer affinity toward foreign countries. J. Sci. Commun., 24(3), 147-167.

3. Nes, E. B., Yelkur, R., Silkoset, R. (2014). Consumer affinity for foreign countries: construct development, buying behavior consequences and animosity contrasts. J. Sci. Commun., 23(4), 774-784.

4. Baker, D. A., Crompton, J. L. (2000). Quality, satisfaction and behavioral intentions. J. Sci. Commun., 27(3), 785-804.

5. Kozak, M. (2001). Repeaters' behavior at two distinct destinations. J. Sci. Commun., 28(3), 784-807.

6. Baloglue, S., Erickson, R. E. (1998). Destination loyalty and switching behavior of travelers: a Markov analysis. J. Sci. Commun., 2(2), 119-127.

7. Oppermann, M. (1998). Destination threshold potential and the law of repeat visitation. J. Sci. Commun., 37(2), 131-137.

8. Jang, S. S., Feng, R. (2007). Temporal destination revisit intention: The effects of novelty seeking and satisfaction. J. Sci. Commun., 28(2), 580-590.

9. Guo, G. X., Zhou X. (2016). A Literature Review of Consumer Affinity and Prospects. J. Sci. Commun., 38(1), 64-71.

10. Yang, Y. W., Sun, G. H., Tong, Z. L. (2018). The Impact Mechanism of Consumer Animosity, Affinity and Ambivalence on Consumers' Outbound Travel Intentions: The Moderating Effects of Culture Proximity. J. Sci. Commun., 370(6), 94-105.

11. Prayag, G., Ryan, C. (2011). The relationship between the 'push'and 'pull'factors of a tourist destination: The role of nationality-an analytical qualitative research approach. J. Sci. Commun., 14(2), 121-143.

12. Kozak, M., Rimmington, M. (2000). Tourist satisfaction with Mallorca, Spain, as an off-season holiday destination. J. Sci. Commun., 38(3), 260-269. 